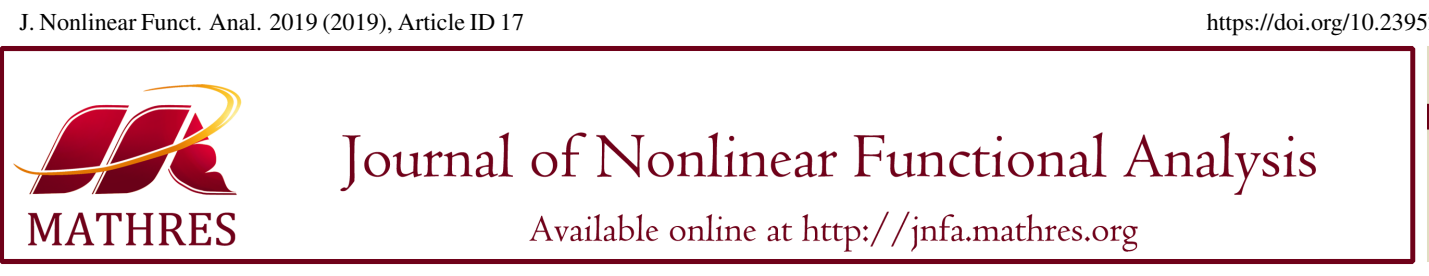

https://doi.org/10.23952/jnfa.2019.17

\title{
A SPLIT EQUILIBRIUM PROBLEM AND A FIXED POINT PROBLEM OF QUASI- $\phi$-NONEXPANSIVE MAPPING IN BANACH SPACES
}

\author{
ZHAOLI MA ${ }^{1}$, LIN WANG $^{2, *}$, YI GAO $^{3}$, YALI LIU ${ }^{3}$ \\ ${ }^{1}$ College of Public Foundation, Yunnan Open University (Yunnan Technical College of National Defence Industry), \\ Kunming 650500, Yunnan, China \\ ${ }^{2}$ Division of Research Administration, Yunnan University of Finance and Economics, Kunming 650221, Yunnan, China \\ ${ }^{3}$ School of Information Engineering, The College of Arts and Sciences, \\ Yunnan Normal University, Kunming 650222, Yunnan, China
}

\begin{abstract}
The purpose of this paper is to propose an iterative algorithm to solve a solution problem which consists of split equilibrium problems and fixed-point problems of quasi- $\phi$-nonexpansive mappings. It is proved that the sequence generated by our proposed iterative algorithm converges strongly to a common solution of the split equilibrium problems and fixed point problems in Banach spaces. As an application, a split optimization problem is investigated.
\end{abstract}

Keywords. Split equilibrium problem; Fixed point problem; Quasi- $\phi$-nonexpansive mapping; Convergence; Banach space.

2010 Mathematics Subject Classification. 47H05, 90C33.

\section{INTRODUCTION}

In 1994, Blum and Oettli [1] introduced the following equilibrium problem which is to find $x \in C$ such that

$$
F(x, y)>0, \forall y \in C \text {. }
$$

The solution set of problem (1.1) is denoted by $E P(F)$, i.e.,

$$
E P(F)=\{x \in C: F(x, y) \geq 0, \forall y \in C\} .
$$

Equilibrium problem (1.1) includes variational inequality problems, optimization problems, Nash equilibrium problems, saddle point problems, fixed point problems, and complementary problems as special cases. Many problems in physics, optimization, and economics can be reduced to finding a solution of equilibrium problem (1.1). In view of these, equilibrium problem (1.1) has been extensively investigated by many authors; see, for example, $[2,3,4,5,6,7]$ and the references therein.

${ }^{*}$ Corresponding author.

E-mail address: wl64mail@aliyun.com (L. Wang).

Received October 14, 2018; Accepted April 10, 2019.

(C)2019 Journal of Nonlinear Functional Analysis 
For modeling inverse problems which arise from phase retrievals and medical image reconstruction [8], Censor and Elfving [9] first introduced the following split feasibility problem (SFP) in finitedimensional spaces in 1994.

Let $C$ and $Q$ be the nonempty closed convex subsets of Hilbert spaces $H_{1}$ and $H_{2}$, respectively. Let $A: H_{1} \rightarrow H_{2}$ be a bounded linear operator. The split feasibility problem (SFP) is formulated as finding a point $x^{*}$ with the property

$$
x^{*} \in C \text { and } A x^{*} \in Q .
$$

The SFP has been found that it can be used in many areas such as image restoration, computer tomograph, and radiation therapy treatment planing $[10,11,12]$.

In 2013, Kazmi and Rizvi [13] considered a new class of split equilibrium problems in the framework of Hilbert spaces.

Let $F: C \times C \rightarrow R$ and $G: Q \times Q \rightarrow R$ be nonlinear bifunctions, $A: H_{1} \rightarrow H_{2}$ is a bounded linear operator. Recall that the split equilibrium problem (SEP) is to find $x^{*} \in C$ such that

$$
F_{1}\left(x^{*}, x\right) \geq 0, \forall x \in C,
$$

and

$$
y^{*}=A x^{*} \in Q \quad \text { solves } F_{2}\left(y^{*}, y\right) \geq 0, \forall y \in Q .
$$

The solution sets of problems (1.4) and (1.5) are denoted by $\operatorname{EP}\left(F_{1}\right)$ and $E P\left(F_{2}\right)$, respectively. And, we denote the solution set of the SEP by $\Omega=\left\{y \in C: y \in E P\left(F_{1}\right)\right.$ such that $\left.A y \in E P\left(F_{2}\right)\right\}$.

Recently, some methods have been proposed to solve the split equilibrium problems based on iterative methods, see, for instance, $[13,14,15,16]$ and the references therein. However, most of the results on the split equilibrium problems were established in Hilbert spaces. A recent result in Banach space can be founded in [17]. There are many difficulties to overcome if one extends the results established in the framework of Hilbert spaces to the framework of Banach spaces, for example, dual mappings are nonlinear and the projection operators may not be nonexpansive.

In this paper, motivated and inspired by the research going on in this direction, we propose a projection algorithm to solve a common solution problem which consists of a split equilibrium problem and a fixedpoint problem of quasi- $\phi$-nonexpansive mappings in Banach spaces. We organize this paper as follows. Section 2 presents some useful definitions and lemmas. Section 3 is devoted to the main convergence theorem. An application is also presented in this section.

\section{PRELIMINARIES}

Let $E$ be a real Banach space with the dual space $E^{*}$. A Banach space $E$ is said to be strictly convex if $\frac{\|x+y\|}{2} \leq 1$ for all $x, y \in U=\{z \in E:\|z\|=1\}$ with $x \neq y$. The modulus of convexity of $E$ is defined by

$$
\delta_{E}(\varepsilon)=\inf \left\{1-\left\|\frac{1}{2}(x+y)\right\|:\|x\| \leq 1,\|y\| \leq 1,\|x-y\| \geq \varepsilon\right\}
$$

for all $\varepsilon \in[0,2] . E$ is said to be uniformly convex if $\delta_{E}(0)=0$, and $\delta_{E}(\varepsilon)>0$ for all $0<\varepsilon \leq 2$.

Recall that the modulus of smoothness of $E, \rho_{E}:[0, \infty) \rightarrow[0, \infty)$, is defined by

$$
\rho_{E}(t)=\sup \left\{\frac{1}{2}(\|x+y\|+\|x-y\|)-1: x \in U,\|y\| \leq t\right\} .
$$

A Banach space $E$ is said to be uniformly smooth if $\frac{\rho_{E}(t)}{t} \rightarrow 0$ as $t \rightarrow 0$. A typical example of uniformly smooth Banach space is $L^{p}$, where $p>1$. More precisely, $L^{p}$ is $\min \{p, 2\}$-uniformly smooth for every 
$p>1$. Let $q$ be a fixed real number with $q>1$. A Banach space $E$ is said to be $q$-uniformly smooth if there exists a constant $c>0$ such that $\rho_{E}(t) \leq c t^{q}$ for all $t>0$. It is well known that every $q$-uniformly smooth Banach space is uniformly smooth.

Let $C$ be a nonempty, closed and convex subset of a strictly convex and reflexive Banach space $E$. The metric projection from $E$ onto $C$ is defined by

$$
P_{C} x=\arg \min _{y \in C}\|x-y\|, x \in E,
$$

which is the unique minimizer of the norm distance. The normalized duality mapping $J$ from $E$ to $2^{E^{*}}$ is defined by

$$
J(x)=\left\{x^{*} \in E^{*}:\left\langle x, x^{*}\right\rangle=\|x\|^{2}=\left\|x^{*}\right\|^{2}\right\}, \forall x \in E,
$$

where $\langle\cdot, \cdot\rangle$ denotes the normalzied duality pairing between $E$ and $E^{*}$. By the Hahn-Banach theorem, $J(x)$ is nonempty; see [18] for more details. If $E$ is a Hilbert space, then $J=I$, where $I$ is the identity mapping. If $E$ is $p$-uniformly convex and uniformly smooth, then its dual space $E^{*}$ is $q$-uniformly smooth and uniformly convex, where $\frac{1}{p}+\frac{1}{q}=1$. In this situation, it is known that the duality mapping $J_{E}^{p}$ is oneto-one, single-valued and satisfies $J_{E}^{p}=\left(J_{E^{*}}^{q}\right)^{-1}$, where $J_{E^{*}}^{q}$ is the duality mapping of $E^{*}$. It is known that if Banach space $E$ is uniformly smooth, then $J$ is uniformly norm-to-norm continuous on each bounded subset of $E$.

Let $E$ is a smooth, reflexive and strictly convex Banach space. Consider the functional defined by

$$
\phi(x, y)=\|x\|^{2}-2\langle x, J y\rangle+\|y\|^{2}, \forall x, y \in E,
$$

where $J$ is the normalized duality mapping of $E$; see $[19,20]$. It is clear that $(2.1)$ is reduced to $\phi(x, y)=$ $\|x-y\|^{2}, \forall x, y \in H$ in Hilbert spaces.

It is obvious from the definition of $\phi$ that

$$
(\|x\|-\|y\|)^{2} \leq \phi(x, y) \leq(\|x\|+\|y\|)^{2}, \forall x, y \in E,
$$

and

$$
\phi\left(x, J^{-1}(\lambda J y+(1-\lambda) J z) \leq \lambda \phi(x, y)+(1-\lambda) \phi(x, z), \forall x, y \in E .\right.
$$

Recall that the generalized projection $\Pi_{C}: E \rightarrow C$, which is due to Alber [19], is defined as follows

$$
\Pi_{C}(x)=\arg \min _{y \in C} \phi(y, x), \forall x \in E .
$$

That is, $\Pi_{C} x=\bar{x}$, where $\bar{x}$ is the unique solution to the minimization problem $\phi(\bar{x}, x)=\inf _{y \in C} \phi(y, x)$.

Definition 2.1. Let $T: C \rightarrow C$ be a mapping. We denote its fixed-point set by $F(T)$. Recall that $T$ is said to be

(i) nonexpansive if

$$
\|T x-T y\| \leq\|x-y\|, \quad \forall x, y \in C ;
$$

(ii) quasi-nonexpansive if $F(T) \neq \emptyset$ and

$$
\|T x-p\| \leq\|x-p\|, \quad \forall x \in C, p \in F(T) ;
$$

(iii) quasi- $\phi$-nonexpansive [21] if $F(T) \neq \emptyset$ and $\phi(p, T x) \leq \phi(p, x), \forall x \in C, p \in F(T)$; 
(iv) asymptotically quasi- $\phi$-nonexpansive $[22,23]$ if $F(T) \neq \emptyset$ and there exists a real sequence $\left\{\mu_{n}\right\} \subset[0, \infty)$ with $\mu_{n} \rightarrow 0$ as $n \rightarrow \infty$ such that

$$
\phi\left(p, T^{n} x\right) \leq\left(1+\mu_{n}\right) \phi(p, x), \forall n \geq 1, x \in C, p \in F(T) .
$$

Definition 2.2. A mapping $T: C \rightarrow C$ is said to be closed if for any sequence $\left\{x_{n}\right\} \subset C$ with $x_{n} \rightarrow x \in C$ and $T x_{n} \rightarrow y$ as $n \rightarrow \infty$, then $T x=y$.

Lemma 2.3. [21] Let $E$ be a real uniformly convex and smooth Banach space and let $C$ be a nonempty closed convex subset of $E$. Let $T: C \rightarrow C$ be a closed asymptotically quasi- $\phi$-nonexpansive mapping with a sequence $\left\{k_{n}\right\} \subset[1, \infty), k_{n} \rightarrow 1$. Then $F(T)$ is a closed convex subset of $C$.

It is easy to see that if $T: C \rightarrow C$ is a quasi- $\phi$-nonexpansive mapping, then $T$ must be an asymptotically quasi- $\phi$-nonexpansive mapping with $\mu_{n}=0$, for each $n \geq 1$.

For solving the equilibrium problem with the bifunction $F: C \times C \rightarrow R$, we assume the following conditions:

(A1) $F(x, x)=0, \forall x \in C$;

(A2) $F(x, y)+F(y, x) \leq 0, \forall x, y \in C$;

(A3) $\lim _{t \downarrow 0} F(t z+(1-t) x, y) \leq F(x, y), \forall x, y, z \in C$;

(A4) For each $x \in C$, the function $y \longmapsto F(x, y)$ is lower semicontinuous and convex.

Lemma 2.4. [24] Let $C$ be nonempty convex closed subset of a uniformly smooth, strictly convex and reflexive Banach space $E$. Let $F: C \times C \rightarrow R$ be a bifunction satisfying $(A 1)-(A 4)$. For any $x \in E$ and $s>0$, define a mapping $T_{s}^{F}: E \rightarrow C$ by

$$
T_{s}^{F}(x)=\left\{z \in C: F(z, y)+\frac{1}{s}\langle y-z, J z-J x\rangle \geq 0, \quad \forall y \in C\right\} .
$$

Then,

(1) $T_{s}^{F}$ is single-valued;

(2)

$$
\left\langle T_{s}^{F} x-T_{s}^{F} y, J T_{s}^{F} x-J T_{s}^{F} y\right\rangle \leq\left\langle T_{s}^{F} x-T_{s}^{F} y, J x-J y\right\rangle, \quad \forall, x, y \in C,
$$

that is, $T_{s}^{F}$ is a firmly nonexpansive mapping;

(3) $F\left(T_{s}^{F}\right)=E P(F)$ is closed and convex.

Lemma 2.5. [20] Let $E$ be a smooth, strictly convex and reflective Banach space and let $C$ be a nonempty convex closed subset of $E$. Then the following conclusions hold:

(a) $\phi\left(x, \Pi_{C} y\right)+\phi\left(\Pi_{C} y, y\right) \leq \phi(x, y), \forall x \in C, y \in E$;

(b) If $x \in E$ and $z \in C$, then $z=\Pi_{C} x$ iff $\langle z-y, J x-J z\rangle \geq 0, \forall y \in C$;

(c) For $x, y \in E, \phi(x, y)=0$ iff $x=y$.

Lemma 2.6. [25] Let $E$ be a uniformly convex and smooth Banach space and let $\left\{x_{n}\right\}$ and $\left\{y_{n}\right\}$ be two sequences of $E$. If $\phi\left(x_{n}, y_{n}\right) \rightarrow 0$ and either $\left\{x_{n}\right\}$ or $\left\{y_{n}\right\}$ is bounded, then $\left\|x_{n}-y_{n}\right\| \rightarrow 0$.

Lemma 2.7. [26] Given a number $r>0$. A real Banach space $E$ is uniformly convex if and only if there exists a continuous strictly increasing function $g:[0, \infty) \rightarrow[0, \infty)$ with $g(0)=0$ such that

$$
\|t x+(1-t) y\|^{2} \leq t\|x\|^{2}+(1-t)\|y\|^{2}-t(1-t) g(\|x-y\|),
$$

for all $x, y \in E$ with $\|x\| \leq r$ and $\|y\| \leq r$, and $t \in[0,1]$. 
Lemma 2.8. [26] Let $E$ be a 2-uniformly smooth Banach space with the best smoothness constants $K>0$. Then the following inequality holds:

$$
\|x+y\|^{2} \leq\|x\|^{2}+2\langle y, J x\rangle+2\|K y\|^{2}, \forall x, y \in E .
$$

\section{MAIN RESULTS}

Throughout this section, we assume that $E_{1}$ is a 2-uniformly convex and 2-uniformly smooth Banach space and $E_{2}$ is a smooth, strictly convex and reflective Banach space. Let $J_{1}$ and $J_{2}$ denote the normalized duality mappings of $E_{1}$ and $E_{2}$, respectively.

Theorem 3.1. Let $E_{1}$ be a 2-uniformly convex and 2-uniformly smooth real Banach space with the best smoothness constant $0<k<\frac{1}{\sqrt{2}}$. Let $E_{2}$ be a smooth, strictly convex and reflective Banach space. Let $C$ and $Q$ be nonempty, closed and convex subset of $E_{1}$ and $E_{2}$, respectively. Assume that $F_{1}: C \times C \rightarrow R$ and $F_{2}: Q \times Q \rightarrow R$ are the bifunctions satisfying $(A 1)-(A 4)$ and that $F_{2}$ is upper semi-continuous in the first argument. Let $S: C \rightarrow C$ be a closed quasi- $\phi$-nonexpansive mapping, and let $A: E_{1} \rightarrow E_{2}$ be a bounded linear operator with adjoint $A^{*}$. Let $\left\{x_{n}\right\}$ be a sequence generated as follows: $x_{1} \in E_{1}, C_{1}=E_{1}$, and

$$
\left\{\begin{array}{l}
u_{n}=T_{s}^{F_{1}}\left(x_{n}+\gamma J_{1}^{-1} A^{*} J_{2}\left(T_{s}^{F_{2}}-I\right) A x_{n}\right), n \geq 1, \\
y_{n}=J_{1}^{-1}\left[\left(1-\alpha_{n}\right) J_{1} x_{n}+\alpha_{n} J_{1} S u_{n}\right], \\
C_{n+1}=\left\{v \in C_{n}: \phi\left(v, y_{n}\right) \leq \phi\left(v, x_{n}\right) ; \phi\left(v, u_{n}\right) \leq \phi\left(v, x_{n}\right)\right\} \\
x_{n+1}=\prod_{C_{n+1}} x_{1},
\end{array}\right.
$$

where $\Pi_{C_{n+1}}$ is the generalized projection of $E_{1}$ onto $C_{n+1},\left\{\alpha_{n}\right\}$ is a sequence in $[\delta, 1), \delta>0$, and $\gamma$ is a positive constant satisfying $0<\gamma<\frac{1}{2\|A\|^{2} k^{2}}$. If $\Gamma=\Omega \cap F(S) \neq \emptyset$, then $\left\{x_{n}\right\}$ converges strongly to a point $p \in \Gamma$, where $p=\Pi_{\Gamma} x_{1}$.

Proof. We divide the proof into five steps.

Step 1 We show that $C_{n}$ is closed and convex for each $n \geq 1$.

It is obvious $C_{1}=E_{1}$ is closed and convex. Assume that $C_{n}$ is closed and convex for some $n \geq 1$. For any $v \in C_{n}$, we know

$$
\begin{gathered}
\phi\left(v, y_{n}\right) \leq \phi\left(v, x_{n}\right) \Leftrightarrow 2\left\langle v, J x_{n}-J y_{n}\right\rangle \leq\left\|x_{n}\right\|^{2}-\left\|y_{n}\right\|^{2}, \\
\phi\left(v, u_{n}\right) \leq \phi\left(v, x_{n}\right) \Leftrightarrow 2\left\langle v, J x_{n}-J u_{n}\right\rangle \leq\left\|x_{n}\right\|^{2}-\left\|u_{n}\right\|^{2} .
\end{gathered}
$$

These imply that $C_{n+1}$ is closed. In addition, it is also easy to see that $C_{n+1}$ also is a convex subset of $E_{1}$. Therefore $\Pi_{C_{n+1}} x_{1}$ is well defined.

Step 2 We prove that $\Gamma \subseteq C_{n}$ for all $n \geq 1$.

Since $E_{1}$ is a 2-uniformly convex and 2-uniformly smooth real Banach space, one has that $E_{1}^{*}$ is also 2-uniformly smooth and 2-uniformly convex. From Lemma 2.4, we know that $T_{s}^{F_{1}}$ and $T_{s}^{F_{2}}$ are firmly 
nonexpansive. Fixing $p \in \Gamma$, we conclude from Lemma 2.8 and (3.1) that

$$
\begin{aligned}
\phi\left(p, u_{n}\right)= & \phi\left(p, T_{s}^{F_{1}}\left(x_{n}+\gamma A^{*} J_{1}^{-1} J_{2}\left(T_{s}^{F_{2}}-I\right) A x_{n}\right)\right. \\
\leq & \phi\left(p, J_{1}^{-1}\left(J_{1} x_{n}+\gamma A^{*} J_{2}\left(T_{s}^{F_{2}}-I\right) A x_{n}\right)\right. \\
= & \|p\|^{2}-2\left\langle p, J_{1} x_{n}+\gamma A^{*} J_{2}\left(T_{s}^{F_{2}}-I\right) A x_{n}\right\rangle+\left\|J_{1} x_{n}+\gamma A^{*} J_{2}\left(T_{s}^{F_{2}}-I\right) A x_{n}\right\|^{2} \\
\leq & \|p\|^{2}-2\left\langle p, J_{1} x_{n}\right\rangle-2\left\langle p, \gamma A^{*} J_{2}\left(T_{s}^{F_{2}}-I\right) A x_{n}\right\rangle+\left\|x_{n}\right\|^{2} \\
& +2 \gamma\left\langle A x_{n}, J_{2}\left(T_{s}^{F_{2}}-I\right) A x_{n}\right\rangle+2 k^{2}\|A\|^{2} \gamma^{2}\left\|\left(T_{s}^{F_{2}}-I\right) A x_{n}\right\|^{2} \\
\leq & \phi\left(p, x_{n}\right)-2 \gamma\left\langle A p-A x_{n}, J_{2}\left(T_{s}^{F_{2}}-I\right) A x_{n}\right\rangle+2 k^{2}\|A\|^{2} \gamma^{2}\left\|\left(T_{s}^{F_{2}}-I\right) A x_{n}\right\|^{2} .
\end{aligned}
$$

In addition, it follows from $A p=T_{s}^{F_{2}} A p$ that

$$
\begin{aligned}
- & 2 \gamma\left\langle A p-A x_{n}, J_{2}\left(T_{s}^{F_{2}}-I\right) A x_{n}\right\rangle \\
= & -2 \gamma\left\langle A p-T_{s}^{F_{2}} A x_{n}, J_{2}\left(T_{s}^{F_{2}}-I\right) A x_{n}\right\rangle-2 \gamma\left\|\left(T_{s}^{F_{2}}-I\right) A x_{n}\right\|^{2} \\
\leq & \gamma\left(\left\|\left(T_{s}^{F_{2}}-I\right) A x_{n}\right\|^{2}+2 k^{2}\left\|A p-T_{s}^{F_{2}} A x_{n}\right\|^{2}\right. \\
& \left.-\left\|A x_{n}-A p\right\|^{2}\right)-2 \gamma\left\|\left(T_{s}^{F_{2}}-I\right) A x_{n}\right\|^{2} \\
\leq & -\gamma\left\|\left(T_{s}^{F_{2}}-I\right) A x_{n}\right\|^{2}+\left(2 k^{2}-1\right) \gamma\left\|A x_{n}-A p\right\|^{2} .
\end{aligned}
$$

Substituting (3.3) into (3.2) and using $0<\gamma<\frac{1}{2\|A\|^{2} k^{2}}$ and $0<k<\frac{1}{\sqrt{2}}$, we have

$$
\begin{aligned}
\phi\left(p, u_{n}\right) & \leq \phi\left(p, x_{n}\right)+\left(2 k^{2}-1\right) \gamma\left\|A x_{n}-A p\right\|^{2}-\gamma\left(1-2 k^{2}\|A\|^{2} \gamma\right)\left\|\left(T_{s}^{F_{2}}-I\right) A x_{n}\right\|^{2} \\
& \leq \phi\left(p, x_{n}\right) .
\end{aligned}
$$

(3.1), (3.4) and Lemma 2.7 yield that

$$
\begin{aligned}
\phi\left(p, y_{n}\right)= & \phi\left(p, J_{1}^{-1}\left[\left(1-\alpha_{n}\right) J_{1} x_{n}+\alpha_{n} J_{1} S u_{n}\right]\right) \\
= & \|p\|^{2}-2\left\langle p,\left(1-\alpha_{n}\right) J_{1} x_{n}+\alpha_{n} J_{1} S u_{n}\right\rangle+\left\|\left(1-\alpha_{n}\right) J_{1} x_{n}+\alpha_{n} J_{1} S u_{n}\right\|^{2} \\
\leq & \|p\|^{2}-2\left(1-\alpha_{n}\right)\left\langle p, J_{1} x_{n}\right\rangle-2 \alpha_{n}\left\langle p, J_{1} S u_{n}\right\rangle+\left(1-\alpha_{n}\right)\left\|x_{n}\right\|^{2} \\
& +\alpha_{n}\left\|S u_{n}\right\|^{2}-\alpha_{n}\left(1-\alpha_{n}\right) g\left(\left\|J_{1} x_{n}-J_{1} S u_{n}\right\|\right) \\
= & \left(1-\alpha_{n}\right) \phi\left(p, x_{n}\right)+\alpha_{n} \phi\left(p, S u_{n}\right)-\alpha_{n}\left(1-\alpha_{n}\right) g\left(\left\|J_{1} x_{n}-J_{1} S u_{n}\right\|\right) \\
\leq & \left(1-\alpha_{n}\right) \phi\left(p, x_{n}\right)+\alpha_{n} \phi\left(p, x_{n}\right)-\alpha_{n}\left(1-\alpha_{n}\right) g\left(\left\|J_{1} x_{n}-J_{1} S u_{n}\right\|\right) \\
\leq & \phi\left(p, x_{n}\right) .
\end{aligned}
$$

It follows from (3.4) and (3.5) that $p \in C_{n+1}$. This implies that $\Gamma \subseteq C_{n}$ for all $n \geq 1$.

Step 3 We prove that $\left\{x_{n}\right\}$ is a Cauchy sequence.

Since $x_{n}=\Pi_{C_{n}} x_{1}$ for all $n \geq 1$, one sees from Lemma 2.5 that

$$
\phi\left(x_{n}, x_{1}\right)=\phi\left(\Pi_{C_{n}} x_{1}, x_{1}\right) \leq \phi\left(p, x_{1}\right)-\phi\left(p, \Pi_{C_{n}} x_{1}\right) \leq \phi\left(p, x_{1}\right), \forall n \geq 1, u \in \Gamma .
$$

It means that $\left\{\phi\left(x_{n}, x_{1}\right)\right\}$ is bounded.

On the other hand, since $x_{n}=\Pi_{C_{n}} x_{1}$ and $x_{n+1}=\Pi_{C_{n+1}} x_{1} \in C_{n+1} \subseteq C_{n}$, we have

$$
\phi\left(x_{n}, x_{1}\right) \leq \phi\left(x_{n+1}, x_{1}\right), \quad \forall n \geq 1,
$$


which yields that $\left\{\phi\left(x_{n}, x_{1}\right)\right\}$ is nondecreasing and bounded. Therefore, the $\operatorname{limit}_{\lim _{n \rightarrow \infty}} \phi\left(x_{n}, x_{1}\right)$ exists. Moreover,

$$
\begin{aligned}
\phi\left(x_{n+1}, x_{n}\right) & =\phi\left(x_{n+1}, \Pi_{C_{n}} x_{1}\right) \\
& \leq \phi\left(x_{n+1}, x_{1}\right)-\phi\left(\Pi_{C_{n}} x_{1}, x_{1}\right) \\
& =\phi\left(x_{n+1}, x_{1}\right)-\phi\left(x_{n}, x_{1}\right),
\end{aligned}
$$

which implies that

$$
\lim _{n \rightarrow \infty} \phi\left(x_{n+1}, x_{n}\right)=0
$$

From Lemma 2.6, we obtain

$$
\lim _{n \rightarrow \infty}\left\|x_{n+1}-x_{n}\right\|=0 \text {. }
$$

For some positive integers $m, n$ with $m \leq n$, Lemma 2.5 sends us to

$$
\begin{aligned}
\phi\left(x_{m}, x_{n}\right) & =\phi\left(x_{m}, \Pi_{C_{n}} x_{1}\right) \leq \phi\left(x_{m}, x_{1}\right)-\phi\left(\Pi_{C_{n}} x_{1}, x_{1}\right) \\
& =\phi\left(x_{m}, x_{1}\right)-\phi\left(x_{n}, x_{1}\right) .
\end{aligned}
$$

Since $\lim _{n \rightarrow \infty} \phi\left(x_{n}, x_{1}\right)$ exists, this leads to

$$
\lim _{n \rightarrow \infty}\left\|x_{n}-x_{m}\right\|=0
$$

Therefore $\left\{x_{n}\right\}$ is a Cauchy sequence.

Step 4 We prove that $\lim _{n \rightarrow \infty}\left\|u_{n}-S u_{n}\right\|=0$ and $\lim _{n \rightarrow \infty}\left\|\left(T_{s}^{F_{2}}-I\right) A x_{n}\right\|=0$.

Since $x_{n+1}=\Pi_{C_{n+1}} x_{1} \in C_{n+1} \subseteq C_{n}$, we have from the definition of $C_{n+1}$

$$
\phi\left(x_{n+1}, u_{n}\right) \leq \phi\left(x_{n+1}, x_{n}\right) \quad \text { and } \quad \phi\left(x_{n+1}, y_{n}\right) \leq \phi\left(x_{n+1}, x_{n}\right) .
$$

Hence,

$$
\lim _{n \rightarrow \infty} \phi\left(x_{n+1}, u_{n}\right)=0 \text { and } \lim _{n \rightarrow \infty} \phi\left(x_{n+1}, y_{n}\right)=0 .
$$

It follows from Lemma 2.6 that

$$
\lim _{n \rightarrow \infty}\left\|x_{n+1}-u_{n}\right\|=0 \quad \text { and } \quad \lim _{n \rightarrow \infty}\left\|x_{n+1}-y_{n}\right\|=0
$$

and

$$
\lim _{n \rightarrow \infty}\left\|y_{n}-u_{n}\right\|=0
$$

It follows from (3.1) that

$$
\begin{aligned}
& \lim _{n \rightarrow \infty} \alpha_{n}\left\|J_{1} S u_{n}-J_{1} x_{n}\right\| \\
& =\lim _{n \rightarrow \infty}\left\|J_{1} y_{n}-J_{1} x_{n}\right\| \\
& \leq \lim _{n \rightarrow \infty}\left(\left\|J_{1} y_{n}-J_{1} u_{n}\right\|+\left\|J_{1} u_{n}-J_{1} x_{n}\right\|\right) .
\end{aligned}
$$

Since $E_{1}$ is a 2-uniformly convex and 2-uniformly smooth Banach space, $J_{1}$ is uniformly norm-to-norm continuous. Since $\lim _{n \rightarrow \infty}\left\|x_{n}-u_{n}\right\|=0$ and $\left\|y_{n}-u_{n}\right\| \rightarrow 0$, we obtain from (3.7) that

$$
\lim _{n \rightarrow \infty}\left\|J_{1} S u_{n}-J_{1} x_{n}\right\|=0
$$

which implies that

$$
\lim _{n \rightarrow \infty}\left\|S u_{n}-x_{n}\right\|=0 .
$$


From (3.4), it follows that

$$
\begin{aligned}
& 2 \gamma\left(1-k^{2}\|A\|^{2} \gamma\right)\left\|\left(T_{s}^{F_{2}}-I\right) A x_{n}\right\|^{2} \\
& \leq \phi\left(p, x_{n}\right)-\phi\left(p, u_{n}\right) \\
& =\|p\|^{2}-2\left\langle p, J_{1} x_{n}\right\rangle+\left\|x_{n}\right\|^{2}-\|p\|^{2}+2\left\langle p, J_{1} u_{n}\right\rangle-\left\|u_{n}\right\|^{2} \\
& =2\left\langle p, J_{1} u_{n}-J_{1} x_{n}\right\rangle+\left\|x_{n}\right\|^{2}-\left\|u_{n}\right\|^{2} \\
& \leq 2\|p\|\left\|J_{1} u_{n}-J_{1} x_{n}\right\|+\left\|x_{n}-u_{n}\right\|\left(\left\|x_{n}\right\|+\left\|u_{n}\right\|\right) .
\end{aligned}
$$

From (3.8) and $2 \gamma\left(1-k^{2}\|A\|^{2} \gamma\right)>0$, we can concluded that

$$
\lim _{n \rightarrow \infty}\left\|\left(T_{s}^{F_{2}}-I\right) A x_{n}\right\|=0 .
$$

Step 5 We show that $\left\{x_{n}\right\}$ converges strongly to an element $p=\Pi_{\Gamma} x_{1}$.

Since $\left\{x_{n}\right\}$ is a cauchy sequence, there exists $p \in E_{1}$ such that $\left\{x_{n}\right\}$ converges strongly to $p$. It follows from (3.8) and the closeness of $S$ that $p=S p$, we obtain $p \in F(S)$. Since

$$
u_{n}=T_{s}^{F_{1}}\left(x_{n}+\gamma J_{1}^{-1} A^{*} J_{2}\left(T_{s}^{F_{2}}-I\right) A x_{n}\right),
$$

we have

$$
F_{1}\left(u_{n}, u\right)+\frac{1}{s}\left\langle u-u_{n}, J_{1} u_{n}-J_{1} x_{n}\right\rangle+\frac{1}{s}\left\langle u-u_{n}, J_{1} x_{n}-J_{1}\left(x_{n}+\gamma J_{1}^{-1} A^{*} J_{2}\left(T_{s}^{F_{2}}-I\right) A x_{n}\right\rangle \geq 0, \quad \forall u \in C .\right.
$$

From $(A 2)$, we obtain

$$
\frac{1}{s}\left\langle u-u_{n}, J_{1} u_{n}-J_{1} x_{n}\right\rangle+\frac{1}{s}\left\langle u-u_{n}, J_{1} x_{n}-J_{1}\left(x_{n}+\gamma J_{1}^{-1} A^{*} J_{2}\left(T_{s}^{F_{2}}-I\right) A x_{n}\right\rangle \geq F_{1}\left(u, u_{n}\right), \quad \forall u \in C .\right.
$$

Taking the limit as $n \rightarrow \infty$ in the above inequality, we have from (A4), (3.6), (3.9) and the fact that $u_{n} \rightarrow p$ that $F_{1}(u, p) \leq 0, u \in C$. Put $z_{t}=t u+(1-t) p$ for all $t \in(0,1]$ and $u \in C$. It means that $z_{t} \in C$ and hence $F_{1}\left(z_{t}, p\right) \leq 0$. Conditions $(A 1)$ and $(A 4)$ yield that

$$
0=F_{1}\left(z_{t}, z_{t}\right) \leq t F_{1}\left(z_{t}, u\right)+(1-t) F_{1}\left(z_{t}, p\right) \leq t F_{1}\left(z_{t}, u\right) .
$$

That is, $F_{1}\left(z_{t}, u\right) \geq 0$.

Let $t \rightarrow 0$. It follows from $(A 3)$ and the proper lower semicontinuity of $\phi$ that

$$
F_{1}(p, u) \geq 0, \quad \forall u \in C .
$$

This implies that $p \in E P\left(F_{1}\right)$.

Next, we show that $A p \in E P\left(F_{2}\right)$. Since $A$ is a bounded linear operator and (3.9), we have

$$
\left\|T_{s}^{F_{2}} A x_{n}-A p\right\| \leq\left\|T_{s}^{F_{2}} A x_{n}-A x_{n}\right\|+\left\|A x_{n}-A p\right\|,
$$

which means

$$
\lim _{n \rightarrow \infty}\left\|T_{s}^{F_{2}} A x_{n}-A p\right\|=0
$$

From the definition of $T_{s}^{F_{2}}$, we have

$$
F_{2}\left(T_{s}^{F_{2}} A x_{n}, y\right)+\frac{1}{s}\left\langle y-T_{s}^{F_{2}} A x_{n}, J_{2} T_{s}^{F_{2}} A x_{n}-J_{2} A x_{n}\right\rangle \geq 0, \quad \forall y \in C .
$$

Since $F_{2}$ is upper semi-continuous in the first argument, we obtain

$$
F_{2}\left(T_{s}^{F_{2}} A p, y\right) \geq 0, \quad \forall y \in C,
$$


which implies that $A p \in E P\left(F_{2}\right)$. So, $p \in \Gamma$. Let $x^{*}=\Pi_{\Gamma} x_{1}, x^{*} \in \Gamma$, we have from $x_{n}=\Pi_{C_{n}} x_{1}$ and $x^{*} \in \Gamma \subseteq C_{n}$

$$
\phi\left(x_{n}, x_{1}\right) \leq \phi\left(x^{*}, x_{1}\right)
$$

This implies that

$$
\phi\left(p, x_{1}\right) \leq \lim _{n \rightarrow \infty} \phi\left(x_{n}, x_{1}\right) \leq \phi\left(x^{*}, x_{1}\right) .
$$

By definition of $x^{*}=\Pi_{\Gamma} x_{1}$, we have $p=x^{*}$. Therefore, $\left\{x_{n}\right\}$ converges strongly to $p \in \Gamma$, where $p=$ $\Pi_{\Gamma} x_{1}$. The proof is completed.

If $E_{1}=E_{2}, C=Q$ and $A=I$ in Theorem 3.1, then we have the following result.

Corollary 3.2. Let E be a 2-uniformly convex and 2-uniformly smooth real Banach space with the best smoothness constant $0<k<\frac{1}{\sqrt{2}}$, and let $C$ be nonempty, closed and convex subset of E. Assume that $F_{1}, F_{2}: C \times C \rightarrow R$ are bifunctions satisfying $(A 1)-(A 4)$ and $F_{2}$ is upper semi-continuous in the first argument. Let $S: C \rightarrow C$ be a closed quasi- $\phi$-nonexpansive mapping. Let $\left\{x_{n}\right\}$ be a sequence generated as follows: $x_{1} \in E, C_{1}=C$, and

$$
\left\{\begin{array}{l}
u_{n}=T_{s}^{F_{1}} T_{s}^{F_{2}} x_{n}, n \geq 1, \\
y_{n}=J_{1}^{-1}\left[\left(1-\alpha_{n}\right) J_{1} x_{n}+\alpha_{n} J_{1} S u_{n}\right], \\
C_{n+1}=\left\{v \in C_{n}: \phi\left(v, y_{n}\right) \leq \phi\left(v, x_{n}\right) ; \phi\left(v, u_{n}\right) \leq \phi\left(v, x_{n}\right)\right\}, \\
x_{n+1}=\Pi_{C_{n+1}} x_{1},
\end{array}\right.
$$

where $\Pi_{C_{n+1}}$ is the generalized projection of $E$ onto $C_{n+1},\left\{\alpha_{n}\right\}$ is a sequence in $[\delta, 1), \delta>0, \gamma$ is a positive constant satisfying $0<\gamma<\frac{1}{2\|A\|^{2} k^{2}}$. If $\Gamma=E P\left(F_{1}\right) \cap E P\left(F_{2}\right) \cap F(S) \neq \emptyset$, then $\left\{x_{n}\right\}$ converges strongly to a point $p \in \Gamma$, where $p=\Pi_{\Gamma} x_{1}$.

Finally, we give an application to a split optimization problem.

Assume that $C$ and $Q$ are nonempty and closed convex subsets of spaces $E_{1}$ and $E_{2}$, respectively. The so-called split optimization problem which is to find a point $x^{*} \in C$ such that

$$
f\left(x^{*}\right) \geq f(x) \text { for all } x \in C,
$$

and

$$
A x^{*}=y^{*} \in Q \text { solves } g\left(y^{*}\right) \geq g(y), \text { for all } y \in Q .
$$

The solution set of the split optimization problem is denoted by the $\Omega$.

Let $f: C \rightarrow R$ and $g: Q \rightarrow R$ be two functions satisfying the following assumptions:

(1) $f(t x+(1-t) y) \leq f(y)$ and $g(t u+(1-t) v) \leq g(v), \quad \forall x, y \in C, u, v \in Q, t \in[0,1]$;

(2) $f(x)$ and $g(y)$ are concave and upper semi-continuous.

Let $F_{1}(x, y)=f(x)-f(y)$ for all $x, y \in C$ and $F_{2}(u, v)=g(u)-g(v)$ for all $u, v \in Q$. If $f$ and $g$ satisfy conditions (1) and (2), then $F_{1}: C \times C \rightarrow R$ and $F_{2}: Q \times Q \rightarrow R$ are two bifunctions satisfying (A1) - (A4). Therefore, the following result can be directly deduced from Theorem 3.1.

Theorem 3.3. Let $E_{1}$ be a 2-uniformly convex and 2-uniformly smooth real Banach space with the best smoothness constant $0<k<\frac{1}{\sqrt{2}}$, and let $E_{2}$ be a smooth, strictly convex and reflective Banach space. Let $C$ and $Q$ be nonempty, closed and convex subset of $E_{1}$ and $E_{2}$, respectively. Let $f: C \rightarrow E_{1}$ and $g: Q \rightarrow E_{2}$ be two functions satisfying conditions (1) and (2). Assume that $F_{1}: C \times C \rightarrow R$ and $F_{2}: Q \times Q \rightarrow R$ are 
the bifunctions defined by $F_{1}(x, y)=f(x)-f(y)$, for all $x, y \in C, F_{2}(u, v)=g(u)-g(v)$, for all $u, v \in Q$ and $F_{2}$ is upper semi-continuous in the first argument. Let $A: E_{1} \rightarrow E_{2}$ be a bounded linear operator with adjoint $A^{*}$, Let $\left\{x_{n}\right\}$ be a sequence generated as follows: $x_{1} \in E_{1}, C_{1}=E_{1}$, and

$$
\left\{\begin{array}{l}
u_{n}=T_{s}^{F_{1}}\left(x_{n}+\gamma J_{1}^{-1} A^{*} J_{2}\left(T_{s}^{F_{2}}-I\right) A x_{n}\right), n \geq 1, \\
y_{n}=J_{1}^{-1}\left[\left(1-\alpha_{n}\right) J_{1} x_{n}+\alpha_{n} J_{1} u_{n}\right], \\
C_{n+1}=\left\{v \in C_{n}: \phi\left(v, y_{n}\right) \leq \phi\left(v, x_{n}\right) ; \phi\left(v, u_{n}\right) \leq \phi\left(v, x_{n}\right)\right\}, \\
x_{n+1}=\Pi_{C_{n+1}} x_{1},
\end{array}\right.
$$

where $\Pi_{C_{n+1}}$ is the generalized projection of $E_{1}$ onto $C_{n+1},\left\{\alpha_{n}\right\}$ is a sequence in $[\delta, 1), \delta>0, \gamma$ is a positive constant satisfying $0<\gamma<\frac{1}{2\|A\|^{2} k^{2}}$. If $\Omega \neq \emptyset$, then $\left\{x_{n}\right\}$ converges strongly to a point $p \in \Omega$, where $p=\Pi_{\Omega} x_{1}$.

\section{Funding}

This paper was supported by the National Natural Science Foundation of China grant No. 11361070.

\section{Acknowledgements}

The authors thank the handling editor and the referees for their valuable suggestions.

\section{REFERENCES}

[1] E. Blum, W. Oettli, From optimization and variational inequalities to equilibrium problems, Math. Student 63 (1994), $123-145$.

[2] X. Qin, S.Y. Cho, Convergence analysis of a monotone projection algorithm in reflexive banach spaces, Acta Math. Sci. 37 (2017), 488-502.

[3] S.S. Chang, H. W. Joseph Lee, C. K. Chan, A new method for solving equilibrium problem fixed point problem and variational inequality problem with application to optimization, Nonlinear Anal. 70 (2009), 3307-3319.

[4] X. Qin, S.S. Chang, Y.J. Cho, Iterative methods for generalized equilibrium problems and fixed point problems with applications, Nonlinear Anal. 11 (2011), 2963-2972.

[5] S. Wang, X. Gong, A.A. Abdou, Y.J. Cho, Iterative algorithm for a family of split equilibrium problems and fixed point problems in Hilbert spaces with applications, Fixed Point Theory Appl. 2016 (2016), Article ID 4.

[6] X. Qin, S. Y. Cho, S. M. Kang, Strong convergence of shrinking projection methods for quasi- $\varphi$-nonexpansive mappings and equilibrium problems, J. Comput. Appl. Math. 234 (2010), 750-760.

[7] W. Takahashi, K. Zembayashi, Strong and weak con-vergence theorems for equilibrium problems and relatively nonexpansive mappings in Banach spaces, Nonlinear Anal 70 (2009), 45-57.

[8] C. Byne, Iterative obligue projection onto convex sets and the split feasibility problem, Inverse Probl. 18 (2002), $441-453$.

[9] Y. Censor, T. Elfving, A multiprojection algorithm using Bregman projections in a product space, Numer. Algo. 8 (1994), 221-139.

[10] Y. Censor, T. Bortfeld, B. Martin, A. Trofimov, A unified approach for inverse problem in intensity-modulated radiation therapy, Phys. Med. Biol. 51 (2006), 2352-2365.

[11] Y. Censor, T.Elfving, N. Kopf, T. Bortfeld, The multiple-sets split feasibility problem and its applications, Inverse Probl. 21 (2005), 2071-2084.

[12] Y. Censor, A. Motova, A. Segal, Pertured projections and subgradient projections for the multiple-sets split feasibility problem, J. Math. Anal. Appl. 327 (2007), 1244-1256.

[13] K.R. Kazmi, S.H. Rizvi, Iterative approximation of a common solution of a split equilibrium problem, a variational inequality problem and a fixed point problem, J. Egypt Math. Soc. 21 (2013), 44-51.

[14] L. Liu, A hybrid steepest descent method for solving split feasibility problems involving nonexpansive mappings, J. Nonlinear Convex Anal. 20 (2019), 471-488. 
[15] D.V. Hieua, Parallel extragradient-proximal methods for split equilibrium problems, Math. Modelling Anal. 21 (2016), 478-501.

[16] Z. Ma, L. Wang, S.S. Chang, W. Duan, Convergence theorems for split equality mixed equilibrium problems with applications, Fixed Point Theory Appl. 2015 (2015), Article ID 31.

[17] B. Guo, P. Ping, H. Zhao, Y. J. Cho, Strong and weak convergence theorems for split equilibrium problems and fixed point problems in Banach spaces, J. Nonlinear Sci. Appl. 10 (2017), 2886-2901.

[18] W. Takahashi, Nonlinear Functional Analysis, Yokohama Publishers, Yokohama, 2000.

[19] Ya. I. Alber, Metric and generalized projection operators in Banach spaces: properties and applications, in: A. G. Kartsatos(Ed.), Theory and Applications of Nonlinear Operators of Accretive and Monotonic Type, pp. 15-50, Marcel Dekker, New York, 1996.

[20] Ya.I. Alber, S. Reich, An iterative method for solving a class of nonlinear operator equations in Banach spaces, Panamer. Math. J. 4 (1994), 39-54.

[21] X. Qin, Y.J. Cho, S.M. Kang, Convergence theorems of common elements for equilibrium problems and fixed point problems in Banach spaces, J. Comput. Appl. Math. 225 (2009) 20-30.

[22] X. Qin, S.Y. Cho, S.M. Kang, On hybrid projection methods for asymptotically quasi- $\phi$-nonexpansive mappings, Appl. Math. Comput. 215 (2010), 3874-3883.

[23] H. Zhou, G. Gao, B. Tan, Convergence theorems of a modified hybrid algorithm for a family of quasi- $\phi$-asymptotically nonexpansive mappings, J. Appl. Math. Comput. 32 (2009), 453-464.

[24] W. Takahashi, K. Zembayashi, Strong and weak convergence theorems for equilibrium problems and relatively nonexpansive mappings in Banach spaces, Nonlinear Anal. 70 (2009), 45-57.

[25] S. Kamimura, W. Takahashi, Strong convergence of a proximal-type algorithm in Banach space, SIAM J. Optim. 13 (2002), 938-945.

[26] H.K. Xu, Inequalities in Banach spaces with applications, Nonlinear Anal. 16 (1991), 1127-1138. 